\title{
Matrix metalloproteinases 2 and 9 activity after intra-articular injection of autologous platelet-rich plasma for the treatment of osteoarthritis in dogs
}

\author{
Mustafa Arican ${ }^{1}$, Atilla Şimşek², Kurtuluş Parlak ${ }^{1}$, Kamil Atli², Gonca Sönmez $^{3}$ \\ Selçuk University, Faculty of Veterinary Medicine, ${ }^{1}$ Department of Surgery, ${ }^{2}$ Department of Virology, \\ ${ }^{3}$ Department of Genetics, Konya, Turkey
}

Received March 8, 2017

Accepted May 15, 2018

\begin{abstract}
Intra-articular injection of platelet-rich plasma offers a promising potential for treatment of osteoarthritis in dogs. Twenty dogs weighing 25 to $50 \mathrm{~kg}$ (mean $38 \mathrm{~kg}$ ) with unilateral stifle osteoarthritis were used for the study. Fourteen dogs were given intra-articular platelet rich plasma treatment and 6 dogs were used as controls. Double centrifuge method was used to obtain platelet-rich plasma. Radiography and ultrasonography of the affected joint were carried out and scores for lameness severity and pain severity were assigned by the attending clinicians. Synovial fluid was collected under sterile conditions at pre-treatment and on the $1^{\text {st }}, 3^{\text {rd }}, 5^{\text {th }}, 7^{\text {th }}, 15^{\text {th }}$ days, and 4,8 and 12 weeks after treatment. Gelatin zymography and Enzyme-linked Immunosorbent Assay were used to determine the synovial fluid levels of matrix metalloproteinase-2 (MMP-2) and metalloproteinase-9 (MMP-9). No adverse effects associated with the injection of the platelet concentrate or saline were observed. Hudson Visual Analog Scale and Canine Brief Pain Inventory scores for all components were non-significantly different between weeks $0,4,12$ for control dogs. Matrix metalloproteinase-9 was totally and MMP-2 was partially inhibited in the platelet-rich plasma group. In the control group, MMP-9 was partially inhibited during the first month and activation started later. Matrix metalloproteinase- 2 was constant in control samples throughout the experimental period. Platelet-rich plasma is a safe and effective method for treatment of dogs with osteoarthritis, possibly more useful for early cases with mild and moderate osteoarthritis. It is suggested that plasma rich platelet should be injected several times at regular intervals instead of a single application.
\end{abstract}

Growth factor, gelatinase, pain scores, lameness, anti-inflammatory effect

Over the past two decades there has been a focus on new therapeutic interventions to reverse or heal progressive joint damage and pathology both in humans and dogs. Osteoarthritis (OA), is a non-inflammatory and non-infectious degeneration of articular cartilage accompanied by bone formation at the synovial margin and by fibrosis of periarticular soft tissues (Schulz 2013). Osteoarthritis in dogs is a slowly progressive, degenerative disease with signs of pain, lameness, and disability. Reportedly, $20 \%$ of the canine population over the age of 1 year have some degree of OA (Roush et al. 2002). Synovial macrophages play a role in triggering inflammatory and destructive states through the production of interleukin-1 $\beta$ (IL-1 $\beta$ ) and tumor necrosis factor- $\alpha$ (TNF- $\alpha$ ), which stimulate chondrocytes to produce inflammatory mediators such as prostaglandin $\mathrm{E}_{2}\left(\mathrm{PGE}_{2}\right)$, nitric oxide $(\mathrm{NO})$, superoxides and proteolytic enzymes: matrix metalloproteinases (MMPs) and A disintegrin and metalloproteinase with thrombospondin motifs (ADAMTS).

The MMPs are a group of zinc-dependent endopeptidases. Increased degradation of extracellular matrix macromolecules is a central event in the disease process of arthritis (Murphy 1995). Matrix metalloproteinases can degrade all components of the extracellular

Address for correspondence:

Mustafa Arican

Department of Surgery

Faculty of Veterinary Medicine

University of Selcuk, Campüs, Konya, Turkey

Phone: +90 3322233591

E-mail: marican@selcuk.edu.tr

http://actavet.vfu.cz/ 
matrix (Murphy 1995). Although the actual mechanism of cartilage destruction is not fully understood, many types of proteinases which are produced by synovial cells, macrophages, neutrophils and by chondrocytes are thought to play a critical role in the degradation of the cartilage matrix (Dean et al. 1989). The profile of MMPs expressed by connective tissues in arthritic joints is sufficient to destroy the structural collagens that comprise articular cartilage and the adjacent tendons and bones as well as the non-collagen matrix molecules that contribute to joint integrity and function (Dean et al. 1989).

Production of MMPs has been shown in chondrocytes, synovial fibroblasts, and inflammatory cells of dogs (Coughlan et al. 1998). In the case of cartilage degradation, MMP-2 and MMP-9 play an important role (Boland et al. 2014). Matrix metalloproteinases are well-known modulators of the extracellular matrix through the cleavage of growth factor receptors. They induce the release of growth factors, independently affecting the extracellular matrix and contributing to all phases of wound healing (Murphy 1995).

Platelet-rich plasma (PRP) is a concentrated source of autologous platelets and contains several different growth factors (platelet-derived growth factor, PDGF), transforming growth factor-beta (TGF- $\beta 1$ ), epidermal growth factor (EGF), and vascular endothelial growth factor (VEGF), and other cytokines that can stimulate healing of soft tissue. They play a major role in the healing process of many tissues (Carter et al. 2003; Kaw as e et al. 2003). These growth factors are known to stimulate biological changes in cell proliferation and matrix metabolism in a diversity of connective tissues and this regenerative competence has led to promising findings (Marx et al. 2004). Platelet-rich plasma has been used as an autologous source of growth factors to induce regeneration of tissues (Anitua et al. 2004; Crovetti et al. 2004), such as articular chondrocytes (Akeda et al. 2006), intervertebral disc cells (Akeda et al. 2006) as well as bone in dental surgery (Kawase et al. 2003). Intra-articular injection of autologous platelets offers a promising potential for treatment of OA in dogs (Fahie et al. 2013; Franklin et al. 2015).

The aim of the present study was to determine the levels of MMP-2 and MMP-9 in synovial fluids samples from OA joints and to assess the efficacy of a single intra-articular injection of an autologous platelet concentrate for the treatment of OA in dogs.

\section{Materials and Methods}

\section{Design of the study}

Twenty dogs of medium to large breed (weighing 25 to $50 \mathrm{~kg}$, mean age 8.6 years) with unilateral stifle OA were used for the study. The study was conducted as a randomized, controlled trial at the Department of Surgery, Faculty of Veterinary Medicine, Selçuk University, Konya, Turkey. The study design followed the published guidelines of and was approved by the institutional Animal Care and Use Committee of the Faculty of Veterinary Medicine, Selçuk University. At the time of study enrollment, fourteen dogs were assigned PRP treatment and six dogs were used as control. They had clinical evidence of unilateral lameness with the cause localized to a single joint. Osteoarthritis was classified as primary or secondary depending on the cause. Secondary osteoarthritis was diagnosed when abnormalities causing joint instability (e.g., cranial cruciate ligament (CCL) rupture) were evident. Dogs with suspected meniscal damage were excluded from the study. Only dogs with no previous treatment, including administration of nutritional supplements were included in the study. The affected joint was examined by radiography and ultrasonography. Scores for severity of lameness and pain were assigned by the attending veterinarian at the clinic.

\section{Radiographic examination}

Radiographs of the affected joints were obtained at weeks $0,4,8$, and 12 . Joints were assessed for evidence of increased synovial fluid volume, displacing the infrapatellar fat pad cranially, periarticular osteophyte formation, enthesiophyte formation, narrowing of the joint space, subchondral bone sclerosis, mineralization of intra-articular and periarticular soft tissues. Osteoarthrosis was scored as mild (1), moderate (2), moderate to severe (2 to 3), or severe (3) as previously described (Innes et al. 2004; Fahie et al. 2013) for twenty dogs. 
Ultrasonographic examinations

Sonographic examination was performed in full weight bearing dogs at weeks $0,4,8$, and 12 . Preparation included the clipping and shaving of the region, followed by antiseptic washing and rinsing with alcohol. Acoustic gel was applied to the region. A diagnostic ultrasound machine (Esaote Pie Medical, Model 410477, Netherlands) with a 5-7.5 MHz convex transducer was used to image the joint in both sagittal and transverse planes for all the dogs.

Evaluation of lameness and pain

Lameness and pain assessments were performed on the $1^{\text {st }}, 3^{\text {rd }}, 5^{\text {th }}, 7^{\text {th }}, 15^{\text {th }}$ day and at weeks 4,8 and 12 after the PRP and saline injections. Scores for severity of lameness and pain were assessed by a clinician using the Hudson Visual Analog Scale (HVAS) (Hudson et al. 2004; Fahie et al. 2013) and Canine Brief Pain Inventory (CBPI) (Brown et al. 2007, 2008), respectively. The study was conducted in a blind manner. Each dog was always assessed by the same veterinarian. The same score was used throughout the 12 weeks for all time points.

Preparation and administration of autologous plasma rich platelets

After these initial evaluations were completed, dogs in the treatment group were sedated with propofol (4-7 mg, i.v.) and a $20 \mathrm{ml}$ blood sample from each dog was obtained by jugular venipuncture. Five millilitres of blood were collected for each tube in combination with Na-citrate. A double centrifuge method was used to obtain PRP. Initially, blood was centrifuged at $96 \mathrm{~g}$ for $10 \mathrm{~min}$, plasma was carefully removed from the centrifuge tube, followed by a second spin at $380 \mathrm{~g}$ for $20 \mathrm{~min}$. All blood samples were sent to the haematology laboratory for platelet, white blood cell (WBC) and haematocrit (Hct) analysis. The platelet concentrate was filtered and injected until sufficient resistance to push back the syringe plunger was reached (mean injection 4-5 ml depending upon the weight of the dog). For the dogs in the control group, arthrocentesis was performed as described for dogs in the treatment group and saline $(0.9 \% \mathrm{NaCl})$ was injected in a similar way to the PRP.

\section{Synovial fluids}

Synovial fluid was collected under sterile conditions before the treatment, on the $1^{\text {st }}, 3^{\text {rd }}, 5^{\text {th }}, 7^{\text {th }}, 15^{\text {th }}$ days and at weeks 4, 8, and 12 after the treatment. Although a slight degree of contamination with blood was inevitable, samples that were severely contaminated (by gross appearance) were discarded and not used for the biochemical marker assays. Synovial fluid samples were subjected to routine cytological analysis and then centrifuged at $5,000 \mathrm{~g}$ for $5 \mathrm{~min}$ to remove cells and debris. Samples were stored in aliquots at $-80^{\circ} \mathrm{C}$.

\section{Gelatin zymography}

Synovial fluid gelatinase activity levels were determined using a modification of a previously described gelatin zymography technique (Coughlan et al. 1998). Synovial fluid samples were diluted 1:2 in a $62.5 \mathrm{mM}$ Tris/ $\mathrm{HCl}$ sample buffer containing $4 \%$ sodium dodecyl sulphate, $25 \%$ glycerol and $0.01 \%$ bromophenol blue $(\mathrm{pH}$ 6.8) before electrophoresis. Each sample $(8 \mu \mathrm{l})$ was added to the gel (polyacrylamide gels containing $2 \mathrm{mg} / \mathrm{ml}$ gelatin) and electrophoresed firstly at $80 \mathrm{~V}$ for approximately $30 \mathrm{~min}$ and secondly at $120 \mathrm{~V}$ for $60 \mathrm{~min}$ in a Minprotean $^{\circledR}$ system (BIO-RAD, California, USA). The effects of 0,50 and $100 \mathrm{mM}$ ethylenediaminetetraacetic acid (EDTA- MMP inhibitor) were also investigated. Synovial fluid samples collected on day 0,30, 60, and 90 after PRP or saline injection were used. To evaluate the clearing of the substrate in the individual gelatinolytic bands, the area of clearing was measured by Image J (Image 2015). The value for the gelatinolytic activity was calculated considering both the area and volume of digestion of the substrate.

Gelatin-degradation enzyme-linked immunosorbent assay (ELISA)

The degree of disintegration of gelatin was measured by ELISA. Double-antibody sandwich ELISA was used for measuring MMP-2 (cat.no: 201-15-0159) and MMP-9 (cat.no: 201-15-0038) Sunred Biological Technology Co., Ltd. (Shanghai, China). The intensity of the reaction product was measured at $450 \mathrm{~nm}$ in an ELISA plate reader (MWGt Lambda Scan 200, Bio-Tek Instruments, Winooski, VT, USA). All samples were assayed in duplicate. The calculation was made following the manufacturer's recommendations.

\section{Statistical analyses}

The clinical values were analyzed by Anderson-Darling in Minitab 14 program. Normal distribution of MMP-2 and MMP-9 ELISA results were statistically evaluated according to the test in multiple experimental setups using the general linear model. Zymogram images were evaluated by Image J software program (Image 2015).

\section{Results}

The dogs used in this study included mix breeds representing a variety of medium to large breeds. The mean body weight was $38 \mathrm{~kg}$ and their age ranged from 8 to 10 years. 
No adverse effects associated with the injection of the platelet concentrate or saline were reported.

\section{Radiographic osteoarthritis scores}

Radiographic OA scores at pre-treatment examination showed that nine dogs had moderate OA (radiographic grade 2), seven had moderate to severe OA (radiographic grade 2-3), and four had severe OA (radiographic grade 3). For all dogs, radiographic scores assigned at week 12 were the same as the scores assigned at pre-treatment.

\section{Ultrasonographic evaluations}

Many of the cases showed capsular distension to detect the relative degree of effusion versus synovial thickening, filled with inflammatory liquid effusion and/or clotted masses of verifying echogenicity and as a result, clearly or indistinctly demarcated from the periarticular soft tissue. Hypertrophy of the synovial membrane, especially in villonodular synovitis, was recognized as a moderately echogenic soft tissue mass. It was difficult to examine the articular cartilage because of the adjacent bone. Ultrasound examination of all joints (included in the study) showed an increasing effusion with thick and moderate homogenous echoic structure at day 0 .

\section{Platelet count, white blood cell count and haematocrit}

The platelet count in the concentrates (mean $1,420,000$ platelets/ $\mu$ ) was significantly $(P<0.001)$ higher than the platelet count in the blood samples, representing a 3.0 or 4.0 fold increase in the platelet count. The WBC count $(1.09 \mathrm{~s} / \mu \mathrm{l})$ for the platelet concentrates was significantly decreased. Haematocrit for the platelet concentrates was significantly lower than Hct for the blood samples.

\section{Evaluation of lameness}

Scores for all components of the HVAS and CBPI were not affected by the clinicians who evaluated the cases. For the dogs in the PRP group, scores for all components of the HVAS (mood, attitude, comfort, activity, playfulness, exercise, walking comfort) (Tables 1, 2) and all components of the CBPI (pain, general activity, the ability to enjoy life, rise, walk, run and climb) were significantly different between pre-treatment and week $4(P<0.05)$, week $8(P<0.05)$, and week $12(P<0.05)$ (Tables 3,4$)$.

Table 1. Clinician assigned scores for components of the Hudson Visual Analog Scale (HVAS) in the Platelet Rich Plasma (PRP) group. Scores were assigned immediately after treatment on day 0 and again on days 30, 60, and 90 . For the components of scoring systems, possible scores range from 1 to 10, with lower scores indicating less lameness or pain.

\begin{tabular}{lccccccccc}
\hline & Day 0 & Day 1 & Day 3 & Day 5 & Day 7 & Day 15 & Day 30 & Day 60 & Day 90 \\
\hline Overall & $6^{5^{\mathrm{a}}}$ & $7^{\mathrm{b}}$ & $8^{\mathrm{b}}$ & $8^{\mathrm{b}}$ & $8^{\mathrm{b}}$ & $9^{\mathrm{b}}$ & $9^{\mathrm{b}}$ & $9^{\mathrm{b}}$ & $10^{\mathrm{b}}$ \\
Mood & $7^{\mathrm{a}}$ & $8^{\mathrm{a}}$ & $8^{\mathrm{b}}$ & $8^{\mathrm{b}}$ & $8 .^{\mathrm{b}} 5$ & $9^{\mathrm{b}}$ & $10^{\mathrm{b}}$ & $9^{\mathrm{b}}$ & $10^{\mathrm{b}}$ \\
Attitude & $7^{\mathrm{a}}$ & $8^{\mathrm{a}}$ & $8^{\mathrm{b}}$ & $8^{\mathrm{b}}$ & $9^{\mathrm{b}}$ & $9^{\mathrm{b}}$ & $9^{\mathrm{b}}$ & $9.5^{\mathrm{b}}$ & $9.5^{\mathrm{b}}$ \\
Comfort & $6^{\mathrm{a}}$ & $7^{\mathrm{b}}$ & $8^{\mathrm{b}}$ & $8.5^{\mathrm{b}}$ & $8^{\mathrm{b}}$ & $9^{\mathrm{b}}$ & $9^{\mathrm{b}}$ & $9^{\mathrm{b}}$ & $9.5^{\mathrm{b}}$ \\
Activity & $5^{\mathrm{a}}$ & $7^{\mathrm{b}}$ & $8^{\mathrm{b}}$ & $9^{\mathrm{b}}$ & $8^{\mathrm{b}}$ & $9^{\mathrm{b}}$ & $9^{\mathrm{b}}$ & $9.5^{\mathrm{b}}$ & $10^{\mathrm{b}}$ \\
Playfulness & $4^{\mathrm{a}}$ & $7^{\mathrm{b}}$ & $8^{\mathrm{b}}$ & $8.5^{\mathrm{b}}$ & $9^{\mathrm{b}}$ & $9^{\mathrm{b}}$ & $9^{\mathrm{b}}$ & $10^{\mathrm{b}}$ & $10^{\mathrm{b}}$ \\
Exercise & $5^{\mathrm{a}}$ & $7^{\mathrm{b}}$ & $8^{\mathrm{b}}$ & $8.5^{\mathrm{b}}$ & $9^{\mathrm{b}}$ & $9^{\mathrm{b}}$ & $9^{\mathrm{b}}$ & $9.5^{\mathrm{b}}$ & $10^{\mathrm{b}}$ \\
Arising stiffness & $6^{\mathrm{a}}$ & $7^{\mathrm{b}}$ & $8^{\mathrm{b}}$ & $9^{\mathrm{b}}$ & $9^{\mathrm{b}}$ & $9^{\mathrm{b}}$ & $10^{\mathrm{b}}$ & $10^{\mathrm{b}}$ & $10^{\mathrm{b}}$ \\
Lying down stiffness & $4^{\mathrm{a}}$ & $3^{\mathrm{b}}$ & $1.5^{\mathrm{b}}$ & $1^{\mathrm{b}}$ & $1^{\mathrm{b}}$ & $1^{\mathrm{b}}$ & $1^{\mathrm{b}}$ & $1^{\mathrm{b}}$ & $1^{\mathrm{b}}$ \\
Walking comfort & $5^{\mathrm{a}}$ & $7^{\mathrm{b}}$ & $8^{\mathrm{b}}$ & $9^{\mathrm{b}}$ & $9^{\mathrm{b}}$ & $9^{\mathrm{b}}$ & $10^{\mathrm{b}}$ & $9.5^{\mathrm{b}}$ & $10^{\mathrm{b}}$ \\
Turning comfort & $4^{5}$ & $6^{\mathrm{b}}$ & $7^{\mathrm{b}}$ & $7.5^{\mathrm{b}}$ & $7^{\mathrm{b}}$ & $8^{\mathrm{b}}$ & $9^{\mathrm{b}}$ & $9^{\mathrm{b}}$ & $9^{\mathrm{b}}$ \\
\hline
\end{tabular}

Superscripts indicate significant differences of the control of each group $(P<0.05)$. 
Table 2. Clinician assigned scores for components of the Hudson Visual Analog Scale (HVAS) in the saline $(0.9 \%$ $\mathrm{NaCl}$ ) solution injected group. Scores were assigned immediately after treatment on day 0 and again on days 30,60 , and 90 . For the components of scoring systems, possible scores range from 1 to 10 , with lower scores indicating less lameness or pain.

\begin{tabular}{lccccccccc}
\hline & Day 0 & Day 1 & Day 3 & Day 5 & Day 7 & Day 15 & Day 30 & Day 60 Day 90 \\
\hline Overall & $6^{\mathrm{a}}$ & $7^{\mathrm{a}}$ & $8^{\mathrm{a}}$ & $8.5^{\mathrm{a}}$ & $8.5^{\mathrm{b}}$ & $9.5^{\mathrm{b}}$ & $9.5^{\mathrm{b}}$ & $9.5^{\mathrm{b}}$ & $10^{\mathrm{b}}$ \\
Mood & $7^{\mathrm{a}}$ & $8^{\mathrm{a}}$ & $8^{\mathrm{a}}$ & $9^{\mathrm{a}}$ & $8.5^{\mathrm{a}}$ & $9^{\mathrm{b}}$ & $9^{\mathrm{b}}$ & $9.5^{\mathrm{b}}$ & $10^{\mathrm{b}}$ \\
Attitude & $7^{\mathrm{a}}$ & $7^{\mathrm{a}}$ & $8^{\mathrm{a}}$ & $8.5^{\mathrm{a}}$ & $9^{\mathrm{a}}$ & $9^{\mathrm{b}}$ & $9.5^{\mathrm{b}}$ & $9.5^{\mathrm{b}}$ & $10^{\mathrm{b}}$ \\
Comfort & $7^{\mathrm{a}}$ & $7^{\mathrm{a}}$ & $8^{\mathrm{a}}$ & $9^{\mathrm{a}}$ & $9^{\mathrm{a}}$ & $9.5^{\mathrm{b}}$ & $9.5^{\mathrm{b}}$ & $9.5^{\mathrm{b}}$ & $10^{\mathrm{b}}$ \\
Activity & $6^{\mathrm{a}}$ & $7^{\mathrm{a}}$ & $7.5^{\mathrm{a}}$ & $8.5^{\mathrm{a}}$ & $9.5^{\mathrm{b}}$ & $9.5^{\mathrm{b}}$ & $9.5^{\mathrm{b}}$ & $10^{\mathrm{b}}$ & $10^{\mathrm{b}}$ \\
Playfulness & $7^{\mathrm{a}}$ & $7^{\mathrm{a}}$ & $8^{\mathrm{a}}$ & $8.5^{\mathrm{a}}$ & $9^{\mathrm{b}}$ & $9^{\mathrm{b}}$ & $9.5^{\mathrm{b}}$ & $10^{\mathrm{b}}$ & $10^{\mathrm{b}}$ \\
Exercise & $6^{\mathrm{a}}$ & $7^{\mathrm{a}}$ & $7.5^{\mathrm{a}}$ & $8.5^{\mathrm{a}}$ & $9^{\mathrm{b}}$ & $8.5^{\mathrm{b}}$ & $9.5^{\mathrm{b}}$ & $10^{\mathrm{b}}$ & $10^{\mathrm{b}}$ \\
Arising stiffness & $6^{\mathrm{a}}$ & $7^{\mathrm{a}}$ & $7.5^{\mathrm{a}}$ & $8^{\mathrm{a}}$ & $9^{\mathrm{a}}$ & $9.5^{\mathrm{b}}$ & $9.5^{\mathrm{b}}$ & $10^{\mathrm{b}}$ & $10^{\mathrm{b}}$ \\
Lying down stiffness & $3^{\mathrm{a}}$ & $1.5^{\mathrm{a}}$ & $1.5^{\mathrm{a}}$ & $1^{\mathrm{a}}$ & $1^{\mathrm{a}}$ & $1^{\mathrm{b}}$ & $1^{\mathrm{b}}$ & $1^{\mathrm{b}}$ & $1^{\mathrm{b}}$ \\
Walking comfort & $7^{\mathrm{a}}$ & $7.5^{\mathrm{a}}$ & $7.5^{\mathrm{a}}$ & $8.5^{\mathrm{a}}$ & $9^{\mathrm{b}}$ & $9.5^{\mathrm{b}}$ & $9.5^{\mathrm{b}}$ & $9.5^{\mathrm{b}}$ & $10^{\mathrm{b}}$ \\
Turning comfort & $5^{\mathrm{a}}$ & $5^{\mathrm{a}}$ & $7^{\mathrm{a}}$ & $7.5^{\mathrm{a}}$ & $8.5^{\mathrm{b}}$ & $8.5^{\mathrm{b}}$ & $8.5^{\mathrm{b}}$ & $9.5^{\mathrm{b}}$ & $9.5^{\mathrm{b}}$ \\
\hline
\end{tabular}

Superscripts indicate significant differences of the control of each group $(P<0.05)$.

Table 3. Clinician assigned scores for components of the Canine Brief Pain Inventory (CBPI) in the Platelet Rich Plasma (PRP) group. Scores were assigned immediately after treatment on day 0 and again on days 30, 60, and 90. For the components of scoring systems, possible scores range from 1 to 10 , with lower scores indicating less lameness or pain.

\begin{tabular}{lccccccccc}
\hline & Day 0 & Day 1 & Day 3 & Day 5 & Day 7 & Day 15 & Day 30 & Day 60 & Day 90 \\
\hline General activity & $5^{\mathrm{a}}$ & $7^{\mathrm{b}}$ & $8^{\mathrm{b}}$ & $9^{\mathrm{b}}$ & $8.5^{\mathrm{b}}$ & $9^{\mathrm{b}}$ & $9^{\mathrm{b}}$ & $9^{\mathrm{b}}$ & $10^{\mathrm{b}}$ \\
Enjoys life & $6^{\mathrm{a}}$ & $7^{\mathrm{b}}$ & $9^{\mathrm{b}}$ & $9^{\mathrm{b}}$ & $9^{\mathrm{b}}$ & $9^{\mathrm{b}}$ & $10^{\mathrm{b}}$ & $9.5^{\mathrm{b}}$ & $10^{\mathrm{b}}$ \\
Can rise & $6^{\mathrm{a}}$ & $8^{\mathrm{b}}$ & $8^{\mathrm{b}}$ & $9^{\mathrm{b}}$ & $9^{\mathrm{b}}$ & $9^{\mathrm{b}}$ & $10^{\mathrm{b}}$ & $9.5^{\mathrm{b}}$ & $10^{\mathrm{b}}$ \\
Can walk & $5^{\mathrm{a}}$ & $7^{\mathrm{b}}$ & $8.5^{\mathrm{b}}$ & $9^{\mathrm{b}}$ & $9^{\mathrm{b}}$ & $10^{\mathrm{b}}$ & $10^{\mathrm{b}}$ & $10^{\mathrm{b}}$ & $10^{\mathrm{b}}$ \\
Can run & $5^{\mathrm{a}}$ & $6^{\mathrm{a}}$ & $8^{\mathrm{b}}$ & $8^{\mathrm{b}}$ & $8^{\mathrm{b}}$ & $9^{\mathrm{b}}$ & $9^{\mathrm{b}}$ & $9^{\mathrm{b}}$ & $10^{\mathrm{b}}$ \\
Can climb & $4^{\mathrm{a}}$ & $5^{\mathrm{b}}$ & $7^{\mathrm{b}}$ & $7^{\mathrm{b}}$ & $7^{\mathrm{b}}$ & $8^{\mathrm{b}}$ & $8^{\mathrm{b}}$ & $8.5^{\mathrm{b}}$ & $9^{\mathrm{b}}$ \\
\hline
\end{tabular}

Superscripts indicate significant differences of the control of each group $(P<0.05)$.

Table 4. Clinician assigned scores for components of the Canine Brief Pain Inventory (CBPI) in the saline $(0.9 \%$ $\mathrm{NaCl}$ ) solution injected group. Scores were assigned immediately after treatment on day 0 and again on days 30,60 , and 90 . For the components of scoring systems, possible scores range from 1 to 10 , with lower scores indicating less lameness or pain.

\begin{tabular}{lccccccccc}
\hline & Day 0 & Day 1 & Day 3 & Day 5 & Day 7 & Day 15 & Day 30 & Day 60 & Day 90 \\
\hline General activity & $6^{\mathrm{a}}$ & $7^{\mathrm{a}}$ & $7.5^{\mathrm{a}}$ & $8.5^{\mathrm{a}}$ & $9^{\mathrm{b}}$ & $9^{\mathrm{b}}$ & $9^{\mathrm{b}}$ & $9.5^{\mathrm{b}}$ & $10^{\mathrm{b}}$ \\
Enjoys life & $6.5^{\mathrm{a}}$ & $7^{\mathrm{a}}$ & $7.5^{\mathrm{a}}$ & $8.5^{\mathrm{a}}$ & $9^{\mathrm{b}}$ & $9^{\mathrm{b}}$ & $9.5^{\mathrm{b}}$ & $9.5^{\mathrm{b}}$ & $10^{\mathrm{b}}$ \\
Can rise & $6.5^{\mathrm{a}}$ & $6.5^{\mathrm{a}}$ & $7.5^{\mathrm{b}}$ & $7.5^{\mathrm{b}}$ & $8.5^{\mathrm{a}}$ & $9^{\mathrm{b}}$ & $9.5^{\mathrm{b}}$ & $9.5^{\mathrm{b}}$ & $10^{\mathrm{b}}$ \\
Can walk & $6.5^{\mathrm{a}}$ & $7^{\mathrm{a}}$ & $8^{\mathrm{a}}$ & $8.5^{\mathrm{a}}$ & $9^{\mathrm{a}}$ & $9^{\mathrm{a}}$ & $9.5^{\mathrm{b}}$ & $9.5^{\mathrm{b}}$ & $10^{\mathrm{b}}$ \\
Can run & $5.5^{\mathrm{a}}$ & $6.5^{\mathrm{a}}$ & $7^{\mathrm{a}}$ & $7.5^{\mathrm{a}}$ & $9^{\mathrm{b}}$ & $9^{\mathrm{b}}$ & $9.5^{\mathrm{b}}$ & $9^{\mathrm{b}}$ & $10^{\mathrm{b}}$ \\
Can climb & $5^{\mathrm{a}}$ & $6^{\mathrm{a}}$ & $6.5^{\mathrm{a}}$ & $6.5^{\mathrm{a}}$ & $8^{\mathrm{b}}$ & $9^{\mathrm{b}}$ & $9^{\mathrm{b}}$ & $9^{\mathrm{b}}$ & $9^{\mathrm{b}}$ \\
\hline
\end{tabular}

Superscripts indicate significant differences of the control of each group $(P<0.05)$.

\section{Gelatin zymography}

There was an increase in the activity of $70 \mathrm{kDa}$ enzyme in pre-treatment synovial fluid samples which was related to MMP-2 activity. Enzyme activity was seen at $204 \mathrm{kDa}$ (MMP- 
9 pro-dimer) and $257 \mathrm{kDa}$ (MMP-9 dimer) (Plate I, Fig. 1). The MMP-9 concentration was totally inhibited in the PRP group. The $70 \mathrm{kDa}$ enzyme (MMP-2 concentration) was partially inhibited in the PRP group. The MMP-2 concentration was present and did not change in saline group (Plate I, Fig. 2). The MMP-9 levels demonstrated a significant decrease in the PRP group and a partial decrease in the saline group within 4 weeks. Nevertheless, MMP-9 enzyme levels were significantly lower within 12 weeks in the PRP treated group compared to the saline-treated group. But enzyme values were increased after 8 weeks in the saline injected group (Plate II, Fig. 3).

\section{Inhibition studies}

The effects of 0, 50, and $100 \mathrm{mM}$ EDTA(MMP inhibitor) were also investigated. Enzyme bands were partially inhibited by $50 \mathrm{mM}$ EDTA and totally inhibited at $100 \mathrm{mM}$. These results indicate that the enzymatic activity observed was due to both MMP-2 and MMP-9 (Plate II, Fig 4).

\section{Gelatin degradation ELISA}

Synovial fluid from all cases demonstrated degradation of gelatin as measured by the gelatin degradation ELISA. The MMP-2 levels were decreased after the first day following PRP injection, however, the MMP-2 levels were raised again within 5 days after injection. The values were shown to be equal in 90 days. The MMP-2 levels also decreased after the first day following saline injection. It was also observed to be at equal values in 90 days post treatment (Plate III, Fig. 5). Pearson correlation of MMP-2 ng/ml and MMP-2 gel did not show any significant correlation between ELISA degradation and gel. The MMP-9 levels in both groups following PRP treatment and saline injection were shown to significantly decrease after 30 days $(P<0.05)$. Reduction of MMP-9 was seen at days 60 and 90 (Plate III, Fig. 6). Nevertheless, the saline-injected group show remittent levels of MMP-9. Enzyme activation was increased within 30 days. Pearson correlation of MMP-9 quantification and gel observation showed significant correlations $(P<0.05)$.

\section{Discussion}

We hypothesized that PRP might have a favourable effect on OA. Our results show that a single intra-articular injection of an autologous platelet concentrate resulted in significant clinical improvements in dogs with OA within 12 weeks, involving a single joint administration as Fahie et al. (2013) previously described. Our data also support the use of platelet therapy as an alternative treatment option for OA.

Treatment choice is varied in dogs with OA (Fox and Millis 2010). A systematic review concluded that for many of the more widely accepted alternatives, there is adequate evidence of efficacy, but that many studies fail to provide sufficient data to draw definite conclusions (Aragon et al. 2007). We believe that arthrocentesis and measurement of potential disease markers can give more objective information about the effects of treatment procedures.

A composite of the 11 questions from all two models will help clinicians determine the degree of lameness when a force plate is not available. The HVAS and CBPI have been evaluated in previous studies (Hudson et al. 2004; Brown et al. 2007, 2008; HielmBjörkman et al. 2011), and are accepted as subjective methods of assessing pain and lameness. The results indicated that clinical efficacy of platelet therapy should be evident to veterinarians only through observation of behavioral changes.

Dogs receiving PRP improved clinically too, but the radiographic scores assigned at week 12 were the same as the scores assigned before the treatment. Ultrasonography examination confirmed a decrease in effusion in the joint in the post-treatment period. Although our study showed that lameness in the saline-injected group had improved by day 
5 , lameness had worsened again by day 21 . This initial improvement may have been the result of a dilution effect of inflammatory mediators by the saline injection.

The composition of the various platelet-rich products that are currently available is subject to considerable research (Dohan Ehrenfest et al. 2010). Four general types of such products are possible (leukocyte rich or poor and fibrin present or absent), and each may have more value in certain applications. The platelet concentrates (mean +1.420 .000$ platelets $/ \mu \mathrm{l}$ ) in the present study had an average of 3- to 4-fold more platelets compared to whole blood without a change in WBC. No adverse effects were reported suggesting that any inflammation that might have occurred as a result of the WBCs was not sufficient to be of clinical relevance.

Woodell-May et al. (2011) reported that the autologous protein solution prepared from PRP comprised both anabolic and anti-inflammatory cytokines and that such combination is useful for treating OA. The MMPs currently considered to play a major role in the turnover of supporting tissues are the collagenases, gelatinases, and stromelysins (Cawston 1995). However, MMPs are secreted in an inactive form, and their activity is regulated by the molecular microenvironment. Therefore, MMP-2 and MMP-9 were measured in our study. Plasma is a major source of the endogenous MMP inhibitor, a2-macroglobulin, which binds MMPs and leads to their clearance by endocytosis. Moreover, tissue inhibitors of MMPs (tissue inhibitor of metalloproteinase TIMP-1, TIMP-2, TIMP-3, and TIMP-4) that are released by platelets bind to and inactivate most MMPs (Cawston 1995). Zymography gives information on the identification of the MMPs and the relative amounts of the enzymes present. The MMPs degrade gelatin, collagen, elastin, aggrecan, osteonectin, cytokines, growth factors, and receptors (Hire et al. 2014). These molecules initiate chemotactic gradients, regulate inflammation, and extravasation of leukocytes into injured tissue (Gill and Parks 2008). Matrix metalloproteinase-9 (gelatinase B) is involved in regulating inflammation by modulating cell migration (Condeelis and Pollard 2006). The ELISA assesses the net gelatinolytic activity in the sample, taking into account the balance between the active enzyme and local inhibitors. Both MMP2 and MMP-9 levels were increased in synovial fluids in pre-treatment analyses of all dogs. Distribution of dogs in osteoarthritis and control groups was performed by random selection. In this study, high enzyme levels in the pretreatment of dogs could be linked to the acute period of OA. Therefore, the enzyme levels were shown to be significantly higher in the figures initially.

The MMP-9 levels were decreased within the 90 days post treatment compared to the pre-treatment levels $(P<0.05)$. These results were confirmed by ELISA and zymography. This study has shown that MMP-2 and MMP-9 enzyme bands were inhibited in the PRP treatment group and there were no changes in the saline-injected group for MMPs activity. Matrix metalloproteinase- 9 is considered to play a critical role in extracellular matrix remodelling and is secreted by inflammatory cells, such as polymorphonuclear neutrophil granulocytes (Condeelis and Pollard 2006). The decrease of enzyme activation showed that MMP-9 was inhibited by the PRP treatment.

The MMP-2 levels decreased after the first day of post-treatment following PRP injection. Nevertheless, levels started to increase again after 5 days. The results were shown to be variable during the 90 days. The levels at 90 days were very similar to the pre-treatment levels, even though the dogs had improved clinically. These results possibly suggested that PRP should be injected several times at regular intervals instead of a single administration.

The anti-nociceptive and anti-inflammatory activities of PRP support its use in OA joints to reduce pain and modulate the disease process (Arnoczky and Shebani-Rad 2013; Xie et al. 2013; Sundman et al. 2014). Yoshida et al. (2004), suggested that PRP acts to induce endogenous hyaluronic acid (HA) production and decrease cartilage 
catabolism. Platelet-rich plasma had almost identical effects as HA on the prevention of inflammatory mediator release and expression of their genes in synoviocytes and cartilage (Yoshida et al. 2004; Xie et al. 2013; Sundman et al. 2014). It has been shown that PRP also has an anabolic effect on chondrocytes, MSCs and synoviocytes with increases in cell proliferation, cartilaginous extra capsular matrix accumulation, and HA secretion. Platelet-rich plasma also has the ability to inhibit inflammation and decrease OA symptoms with a clinically acceptable and reliable profile (Xie et al. 2013). Preliminary studies show that PRP applications inhibited especially MMP-9 enzyme levels that decreased within a month after intra-articular injection. Previously, it was reported in humans that repeated intra-articular injections could cause moderate pain, swelling and mild effusion that last a few days (Spakova et al. 2012). In our study, we did not observe any adverse effect such as pain, swelling or effusion.

Platelet-rich plasma seems to be a safe and effective method for treating dogs with OA. In vivo data and clinical results are encouraging. The entire procedure, from initial sedation to completion of the intra-articular injection, takes about 35-40 min. Platelet-rich plasma could be more useful for early cases with mild and moderate OA. It has been suggested that PRP has an anti-inflammatory effect. The levels of enzymes that are effective in the disease mechanism were decreased following PRP injection, and increased again within 20-30 days following PRP injection. For this reason, frequent use is recommended. Platelet-rich plasma should be injected several times at regular intervals instead of a single application. The conclusions drawn from this study are limited by the number of cases studied.

\section{Acknowledgements}

This work was supported by The Scientific and Technological Research Council of Turkey (TÜBİTAK, Project no. 2130175).

\section{Conflict of Interest}

The authors declare no financial or other conflicts related to this report.

\section{References}

Akeda K, An HS, Okuma M, Attawia M, Miyamoto K, Thonar EJ-MA, Lenz ME, Sah MD 2006: Platelet-rich plasma stimulates porcine articular chondrocyte proliferation and matrix biosynthesis. Osteoarthr Cartilage 14: $1272-1280$

Anitua E, Andia I, Ardanza B, Nurden P, Nurden AT 2004: Autologous platelets as a source of proteins for healing and tissue regeneration. Thromb Haemost 91: 4-15

Aragon CL, Hofmeister EH, Budsberg SC 2007: Systematic review of clinical trials of treatments for osteoarthritis in dogs. J Am Vet Med Assoc 230: 514-521

Arnoczky SP, Shebani-Rad S 2013: The basic science of platelet-rich plasma (PRP): what clinicians need to know. Sports Med Arthrosc 21: 180-185

Boland L, Danger R, Cabon Q, Rabillard M, Brouard S, Bouvy B, Gauthier O 2014: MMP-2 as an early synovial biomarker for cranial cruciate ligament disease in dogs. Vet Comp Orthop Traumatol 3: 210-215

Brown DC, Boston RC, Coyne JC, Farrar JT 2008: Ability of the canine brief pain inventory to detect response to treatment in dogs with osteoarthritis. J Am Vet Med Assoc 233: 1278-1283

Brown DC, Boston RC, Coyne JC, Farrar JT 2007: Development and psychometric testing of an instrument designed to measure chronic pain in dogs with osteoarthritis. Am J Vet Res 68: 631-637

Carter CA, Jolly DG, Worden Sr CE, Hendren DG, Kane CJM 2003: Platelet-rich plasma gel promotes differentiation and regeneration during equine wound healing. Exp Mol Pathol 74: 244-255

Cawston T 1995: Proteinases and inhibitors. Br Med Bull 51: 385-401

Condeelis J, Pollard JW 2006: Macrophages: obligate partners for tumor cell migration, invasion, and metastasis. Cell 124: 263-266

Coughlan AR, Robertson DH, Bennett D, May C, Beynon RJ, Carter SD 1998: Matrix metalloproteinases 2 and 9 in canine rheumatoid arthritis. Vet Rec 143: 219-223 
Creaney L, Hamilton B 2008: Growth factor delivery methods in the management of sports injuries: the state of play. Br J Sports Med 42: 314-320

Crovetti G, Martinelli G, Issi M, Barone M, Guizzardi M, Campanati B, Moroni M, Carabelli A 2004: Platelet gel for healing cutaneous chronic wounds. Transfus Apher Sci 30: 145-151

Dean DD, Martel-Pelletier J, Pelletier JP, Howell DS, Woessner JF 1989: Evidence for metalloproteinase and metalloproteinase inhibitor imbalance in human osteoarthritic cartilage. J Clin Invest 84: 678-685

Dohan Ehrenfest DM, Bielecki T, Del Corso M, Inchingolo F, Sammatino G 2010: Shedding light in the controversial terminology for platelet-rich products: platelet-rich plasma (PRP), platelet-rich fibrin (PRF), platelet-leukocyte gel (PLG), preparation rich in growth factors (PRGF), classification and commercialism. J Biomed Mater Res A 95: 1280-1282

Fahie MA, Ortolano GA, Gurecio V, Schaffer JA, Johnston G, Au J, Hettlich BA, Philips T, Allen MJ, Bertone AL 2013: A randomized controlled trial of the efficacy of autologous plasma rich platelet therapy for the treatment of osteoarthritis in dogs. J Am Vet Med Assoc 243: 1291-1297

Fox SM, Millis D 2010: Multimodal management of canine osteoarthritis. London: Manson Publishing Ltd, 96.

Franklin SP, Garner BC, Cook JL 2015: Characteristics of canine platelet-rich plasma prepared with five commercially available systems. Am J Vet Res 76: 822-827

Gill SE, Parks WC 2008: Metalloproteinases and their inhibitors: regulators of wound healing. Int J Biochem Cell Biol 40: 1334-1347

Hielm-Björkman AK, Kapatkin AS, Rita HJ 2011: Reliability and validity of a visual analogue scale used by owners to measure chronic pain attributable to osteoarthritis in their dogs. Am J Vet Res 72: 601-607

Hire JM, Evanson JL, Johnson PC, Zumbrun SD, Guyton MK, McPherson III JC, Bojerscu JA 2014: Variance of matrix metalloproteinase (MMP) and tissue inhibitor of metalloproteinase (TIMP) concentrations in activated, concentrated platelets from healthy male donors. J Orthop Surg Res 9: 29

Hudson JT, Slater MR, Taylor L, Scott M, Kerwin SC 2004: Assessing repeatability and validity of a visual analogue scale questionnaire for use in assessing pain and lameness in dogs. Am J Vet Res 65: 1634-1643

Image J 20151.46 software (NIH, http://imagej.nih.gov/ij/)

Innes JF, Costello M, Barr FJ, Rudolf H, Barr ARS 2004: Radiographic progression of osteoarthritis of the canine stifle joint: a prospective study. Vet Radiol Ultrasound 45: 143-148

Kawase T, Okuda K, Wolff L, Yoshie H 2003: Platelet-rich plasma-derived fibrin clot formation stimulates collagen synthesis in periodontal ligament and osteoblastic cells in vitro. J Periodontal 74: 858-864

Marx RE 2004: Platelet-Rich Plasma: Evidence to Support Its Use. Int J Oral Maxillofac Surg 62: 489-496

Murphy G 1995. Matrix metalloproteinases and their inhibitors. Acta Ortho Scandi Suppl 266: 55-60

Roush JK, McLaughlin RM, Radlinsky MG 2002: Understanding the pathophysiology of osteoarthritis. Vet Med 97: 108-117

Spaková T, Rosocha J, Lacko M, Harvanova D, Gharaibeh A 2012: Treatment of knee joint osteoarthritis with autologous platelet-rich plasma in comparison with hyaluronic acid. Am J Phys Med Rehabil 91: 411-441

Schulz KS 2013: Degenerative Joint Disease. In; Fossum TW (Ed.): Small Animal Surgery. Fourth Edition. Elsevier, USA, pp 1226-1229

Sundman EA, Cole BJ, Karas V, Valle CD, Tetreault MW, Mohammed HO, Fortier LA 2014: The Anti-inflammatory and Matrix Restorative Mechanisms of Platelet-Rich Plasma in Osteoarthritis. Am J Sports Med 42: 35-41

University of Pennsylvania School of Veterinary Medicine Veterinary Clinical Investigations Center 2012: Canine Brief Pain Inventory. Available at: research.vet.upenn.edu/PennChart/Available Tools/tabid/1969/ Default.aspx.

Woodell-May J, Matuska A, Oyster M 2011: Autologous protein solution inhibits MMP-13 production by IL-1beta and TNFalpha-stimulated human articular chondrocytes. J Orthop Res 29: 1320-1326

Xie X, Wu H, Zhao S, Xie G, Huangfu X, Zhao J 2013: The effect of platelet-rich plasma on patterns of gene expression in a dog model of anterior cruciate ligament reconstruction. J Surg Res 180: 80-88

Yoshida M, Sai S, Marumo K,Tanaka T, Itano N,Kimata K, Fujii K 2004: Expression analysis of three isoforms of hyaluronan synthase and hyaluronidase in the synovium of knees in osteoarthritis and rheumatoid arthritis by quantitative real-time reverse transcriptase polymerase chain reaction. Arthritis Res Ther 6: R514-R520 
Plate I

Arican M. et al.: Matrix metalloproteinases ... pp. 127-135

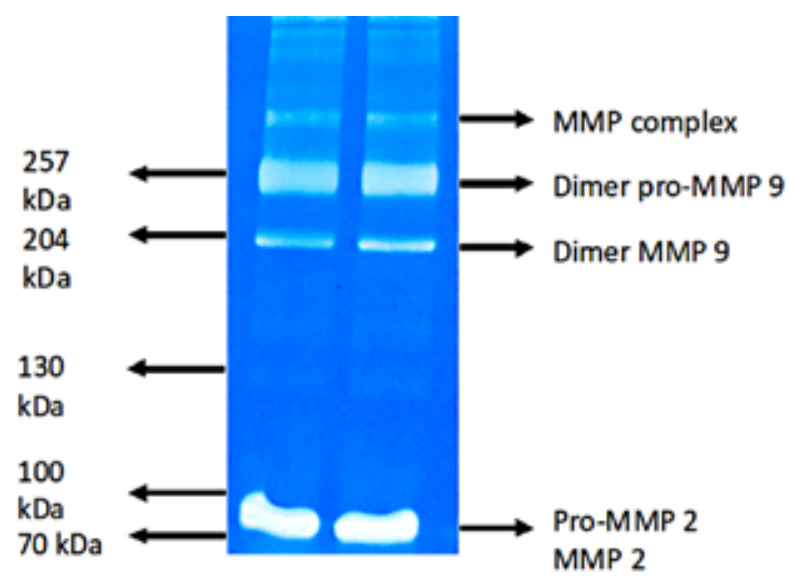

MMP-2 - matrix metalloproteinase-2; MMP-9 - matrix metalloproteinase-9

Fig. 1. The $70 \mathrm{kDa}$ enzyme in pre-treatment synovial fluids samples. This was due to MMP-2 activity. Enzyme activity was seen at $204 \mathrm{kDa}$ (MMP-9 pro-dimer) and $257 \mathrm{kDa}$ (MMP-9 dimer).

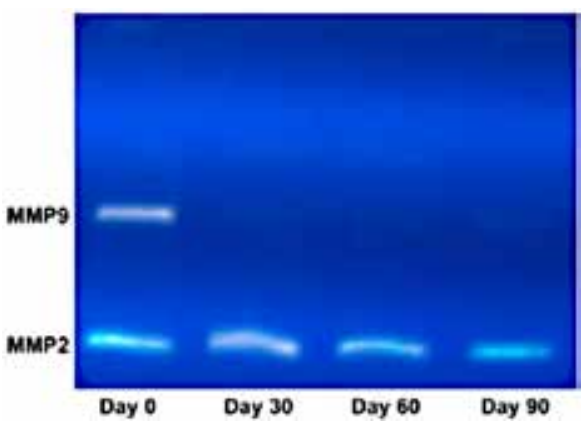

a) PRP treated group

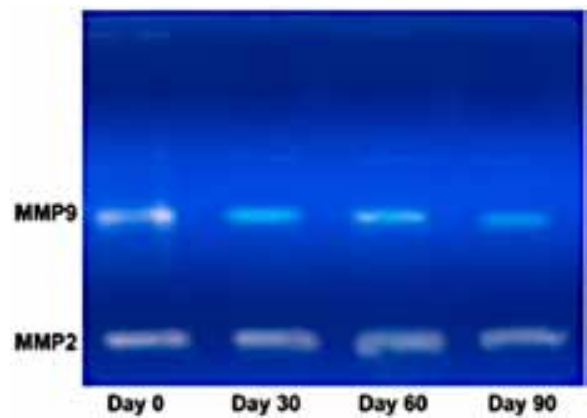

b) Saline $(0.9 \% \mathrm{NaCl})$ treated group

PRP - platelet rich plasma; MMP-2 - matrix metalloproteinase-2; MMP-9 - matrix metalloproteinase-9

Fig. 2. a) PRP treated group; $204 \mathrm{kDa}$ enzyme band (MMP-9) in pre- treatment synovial fluid samples. The band was totally inhibited in the PRP group. The $70 \mathrm{kDa}$ enzyme (MMP-2) was partially inhibited in PRP group. b) MMP-9 was partially inhibited within first month and then re-activated; MMP-2 activation was not changed in the saline-treated group. 
Plate II
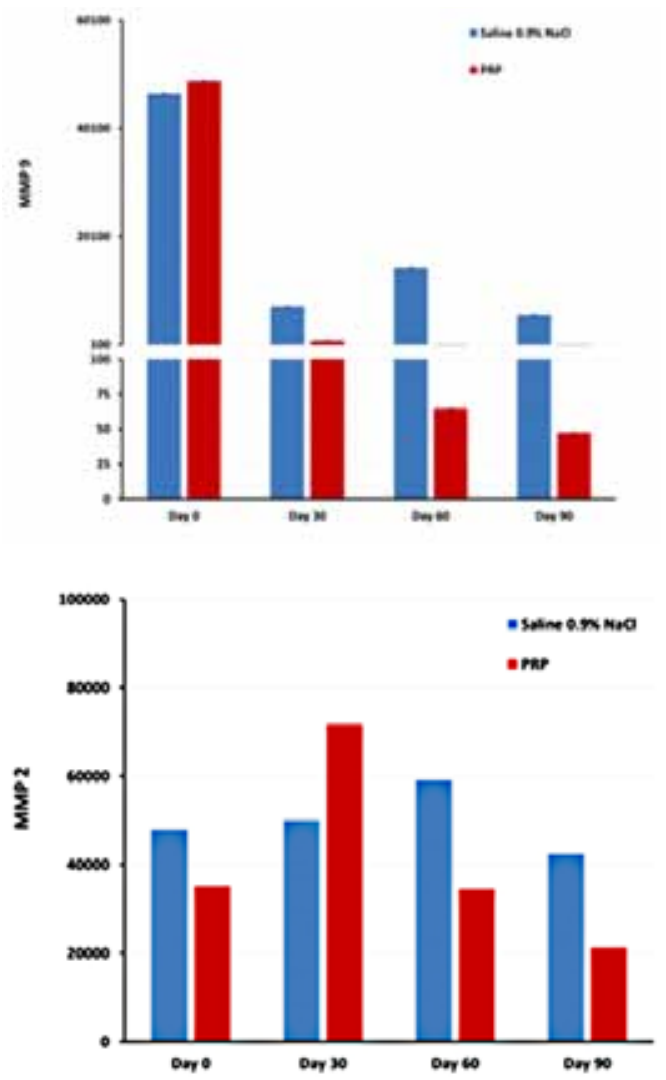

PRP - platelet rich plasma; MMP-2 - matrix metalloproteinase-2; MMP-9 - matrix metalloproteinase-9

Fig. 3. The MMP-9 and MMP-2 activation levels throughout the 90 days of the experiment

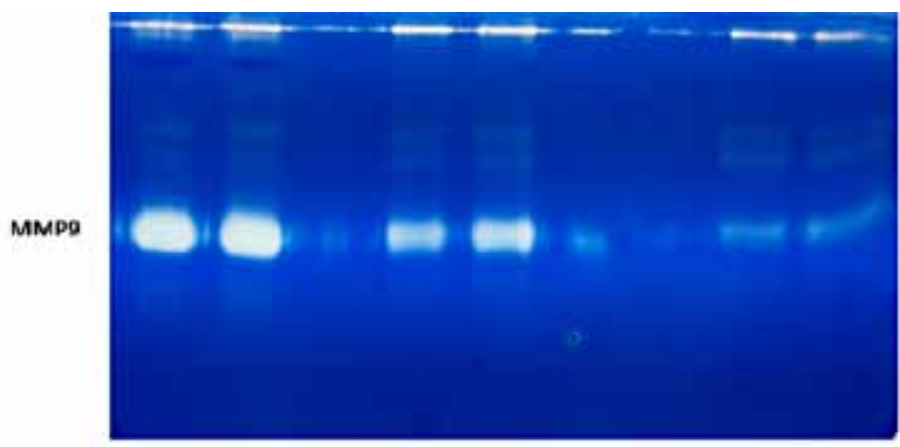

MMP - matrix metalloproteinase-2; MMP-9 - matrix metalloproteinase-9; EDTA ethylenediaminetetraacetic acid

Fig. 4. The effects of $0 \mathrm{mM}, 50 \mathrm{mM}$ and $100 \mathrm{mM}$ EDTA (MMP inhibitor) 
Plate III

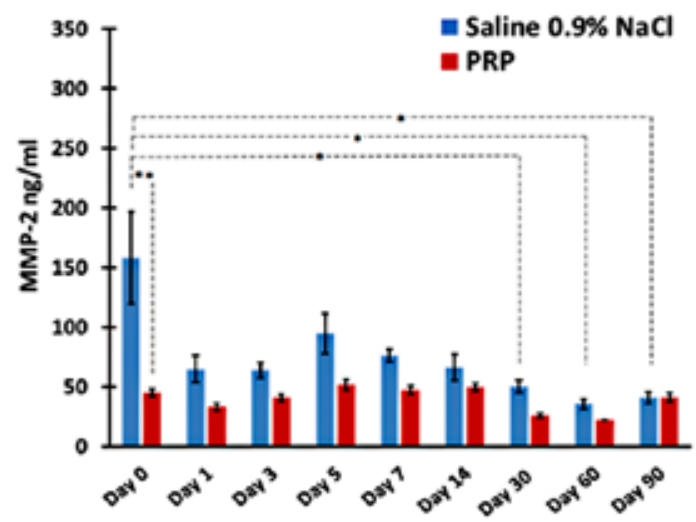

PRP - platelet rich plasma; MMP-2 - matrix metalloproteinase-2; ELISA - Enzyme-linked Immunosorbent Assay

Fig. 5. Normal distribution of MMP-2 ELISA results

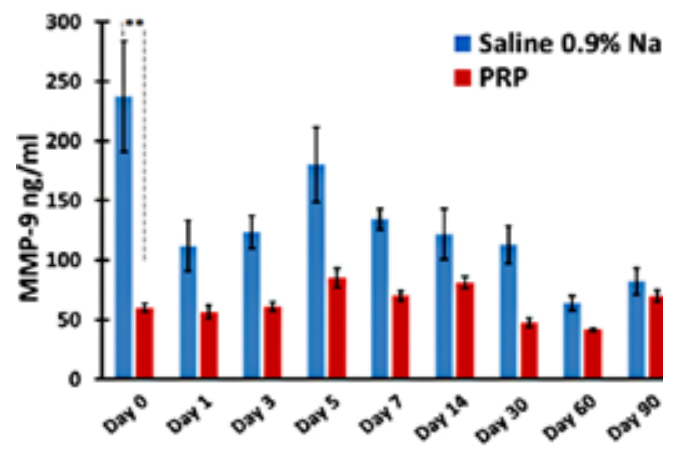

PRP - platelet rich plasma; MMP-9 - matrix metalloproteinase-2; ELISA - Enzyme-linked Immunosorbent Assay

Fig. 6. Normal distribution of MMP-9 ELISA results 